\title{
Numerical Study of the Interaction between a Head Fire and a Backfire Propagating in Grassland
}

\author{
DOMINIQUE MORVAN ${ }^{1}$, SOFIANE MERADJI ${ }^{1}$, and WILLIAM MELL ${ }^{2}$ \\ ${ }^{1}$ Laboratoire M2P2, Université de la Méditerranée, UNIMECA \\ 60 rue Joliot Curie Technopôle de Château Gombert 13453 Marseille cedex 13 France \\ ${ }^{2}$ Building and Fire Research Laboratory \\ National Institute of Standards and Technology \\ NOAA/OAR/ESL/GSD 325 Broadway R/GSD7 \\ Boulder, CO 80305
}

\begin{abstract}
One of the objectives of this paper was to simulate numerically the interaction between two line fires ignited in a grassland, on a flat terrain, perpendicularly to the wind direction, in such a way that the two fire fronts (a head fire and a backfire) propagated in opposite directions parallel to the wind. The numerical simulations were conducted in 3-D using the new fuel element module recently implemented in WFDS. We chose grassland for the fuel layer, because it represents certainly one of the most studied eco-system, in the frame of experimental campaigns to study the behavior of surface fires at large scale. The aim of this numerical study is to understand what are the physical phenomena and the favorable conditions of ignition of a counter fire, during a fire suppression operation. The preliminary results highlighted that the two fire fronts interacted only at a relative short distance $(10-20 \mathrm{~m})$, following this scenario:

- The thermal plume above the head fire (representing the main fire front) formed a sort of shelter, protecting the backfire to the direct effect of the wind flow,

- Before the merging between the two fire fronts, an in-draft flow was observed ahead of the head fire, promoting and accelerating the propagation of the backfire.

During the last step of the merging of the two fire fronts, a sudden increase of the heat release rate was observed, indicating a significant interaction between the two fires, which can potentially represent a safety problem for people in charge of this kind of operation.
\end{abstract}

KEYWORDS: suppression, forest fire, wildfires, physical modeling.

\section{INTRODUCTION}

The firefighter services estimate that aerial suppression of forest fires has limited effects when the fire line intensity exceeds a threshold level of $7000 \mathrm{~kW} / \mathrm{m}$ [1]. In many situations this critical value is far exceeded $[2,3]$ for crown fires in forest, but also for surface fires propagating in grassland and sustained even by moderate wind conditions [4]. Consequently, the reduction of the fuel load between the fire front and a control line, represents an alternative and potentially effective method (if it is used in suitable conditions) to stop or to reduce the propagation of a fully developed wildfire. This operation can be accomplished by using mechanical means (bulldozer) or by the ignition of a suppression fire (also called counter fire or backfire) [5]. Such traditional suppression techniques have recently been reintroduced by some firefighter services when classical terrestrial or aerial means were not sufficiently effective. Formally one can distinguish two methods [6]:

- Burn-out operations, consisting in the use of techniques very similar to prescribed burning.

- Suppression fire (more aggressive than the previous one), for which a fire line is ignited as close as possible to the main fire front.

The knowledge concerning the optimal conditions in the implementation of a backfiring operation remains mainly empirical [1]. The ideal situation to ignite a counter fire is obtained when the meteorological and topological conditions governing the behavior of the main fire front result in the development of an indraft flow in the region between the two fire fronts. In this case, we can consider that the manmade backfire will be aspirated by this in-draft flow (in the opposite direction compared to the wind flow), assuring the sufficient elimination of the surface fuel in the region located between the main fire front and the control line. Very few fundamental studies were dedicated to study this problem, some very 
preliminary experimental results were collected at small scale in fuel beds [7], on the field, the propagation and the interaction between a head fire and a backfire were analyzed from experimental fires conducted in small plots of shrubs, in the frame of the EU program FIREPARADOX [8,9]. The problem concerning the conditions of development of an in-draft flow was studied numerically in 2-D using FDS, in a static fire configuration (a single burner) [10]. More recently numerical simulations carried out in both 2-D and 3-D were conducted to study the propagation and the interaction between two line fires, ignited in homogeneous grassland, on a flat terrain [11,12]. In 2-D [11], calculations were conducted using the multiphase code FIRESTAR, for two eco-systems (grassland and Mediterranean shrubland). Some preliminary 3-D simulations were performed using WFDS [11] and FIRETEC [12]. Compared to the present study, the results presented in [11] did not resolve explicitly the vegetation layer and the source/sink terms resulting from the interaction between the vegetation and the atmosphere. The fuel layer was only treated as a boundary condition, to evaluate the mass flux of chemical species resulting from the drying and the pyrolysis process. These different studies were focused on the action of the wind flow conditions, upon the development of the in-draft flow between the two fire fronts, and more generally on the physical phenomena associated with the interaction between the two fires. One of the major conclusions of these numerical studies, was that on a flat terrain and for relatively moderate wind conditions $\left(U_{10}<10 \mathrm{~m} / \mathrm{s}\right)$, the two fire fronts can interact significantly at relatively short distance $(\sim 10$ $20 \mathrm{~m}$ ). This interaction does not depend solely on the development of an in-draft flow ahead of the main fire front, but very often it is materialized by the shelter effect induced by the thermal plume above the main front, sheltering the secondary, downwind front (backfire) from the effects of the wind flow. It is in this context that we proposed to simulate the behavior of two line fires separated by a distance equal to 50 $\mathrm{m}$ and ignited simultaneously. Concerning the fuel layer, we chose grassland, because grass fires were certainly the most studied configuration for the understanding of surface fires, for which there exists a large data base to compare numerical results and experimental data [13]. Because this kind of fuel is characterized by low fuel moisture content, the behavior of fires can be sometimes erratic, difficult to predict, these elements can be at the origin of some safety problems which need a particular attention [14].

\section{MATHEMATICAL AND PHYSICAL MODEL}

The problem was simulated using a detailed physical model, based on a multiphase formulation $[15,16]$. The computer model used here is called WFDS for Wildland-urban interface Fire Dynamics Simulator (WFDS). This model is an extension of the enclosure fire model FDS [17] to include the presence and burning of vegetation. The numerical approach solves the three-dimensional time-dependent equations governing fluid motion, combustion, and heat transfer, associated with the ignition and the development of a fire. To avoid the problem associated with the propagation of acoustic waves (which do not play an important role in these problems), the problem was formulated using a low Mach number approach. Concerning the turbulence model, it is based on a large eddy simulation (LES) approach, using a constant coefficient Smagorinsky in the sub-grid scale model. The turbulence/combustion interaction was solved using the eddy dissipation concept (EDC), assuming that the gas mixture resulting from the thermal decomposition of solid fuel particles can be approximated using the following chemical formula [18]: $\mathrm{C}_{3.4} \mathrm{H}_{6.2} \mathrm{O}_{2.5}$. All the details of the model are reported in Ref. [16]. In addition to the set of validation and verification tests carried out for FDS, WFDS has been validated at the laboratory scale using measurements from Douglas fir tree burn experiments [16] and at field scale using measurements in Australian grassland fires [19].

In the numerical simulations conducted here, two line fires were ignited, one at the upwind and one at the downwind edges of a $20 \mathrm{~m} \times 50 \mathrm{~m}$ (width $\times$ length) grassland plot. The long axis of the plot is aligned with the wind. The physical properties characterizing the fuel layer (listed in Table 1) are equivalent to a coarse grass, comparable to those encountered during the experimental campaign carried out in Australia [13]. To reduce the impact of some uncertainties concerning some open boundary conditions, this plot was immersed in a larger domain $(120 \mathrm{~m} \times 130 \mathrm{~m})$, the upper limit was positioned $40 \mathrm{~m}$ above the ground level. 
Table 1. Physical properties characterizing the fuel layer.

\begin{tabular}{|l|c|}
\hline Fuel density $\left(\mathrm{kg} / \mathrm{m}^{3}\right)$ & 500 \\
\hline Fuel packing ratio $\times 10^{3}$ & 2 \\
\hline Fuel moisture content $(\%)$ & 5 \\
\hline Fuel depth $(\mathrm{m})$ & 0.7 \\
\hline Surface area to volume ratio $\left(\mathrm{m}^{-1}\right)$ & 4000 \\
\hline Leaf area index $(\mathrm{LAI})$ & 1.4 \\
\hline
\end{tabular}

As discussed in a review paper [20], two mechanisms govern the heat transfer between the flame and the unburned fuel and consequently the behavior of the fire: radiation and convection. In many situations the computational grid cell size is limited by the length scale characterizing the radiation heat transfer, i.e. the extinction length scale, defined as following:

$\delta_{R}=\frac{4}{\alpha_{S} \sigma_{S}}$

where $\alpha_{S}$ and $\sigma_{S}$ designate the average volume fraction and the surface area-to-volume ratio characterizing the solid fuel layer. Using the fuel properties listed in Table 1, this parameter was equal to $0.5 \mathrm{~m}$, consequently the grid sizes along the horizontal directions were chosen to be equal to $\Delta x=\Delta y=0.25 \mathrm{~m}$. Along the vertical direction, we used a variable grid size $\Delta z$ ranged between 0.05 near the ground level to $2 \mathrm{~m}$ at the top of the computational domain. Before igniting the fire lines, the flow field was initialized during a certain period (ranged between $120 \mathrm{~s}$ and $30 \mathrm{~s}$, depending on the wind speed) using a power law, velocity profile at the inlet (also used as a boundary condition during all the calculation):

$U_{X}(Z)=U_{H}\left(\frac{Z}{H}\right)^{1 / 7}$

For all calculations the same reference height $H=10$, was chosen to define the wind conditions, consequently $U_{H}=U_{10}$ designates in this paper the $10 \mathrm{~m}$ open wind speed.

\section{RESULT AND DISCUSSION}

A set of calculations simulating the propagation of a surface fire (head fires) through a grassland were conducted as a preliminary study and compared with data collected during a large scale experimental campaign carried out in Australia [13]. The evolution of the rate of spread (ROS) of the head fire, evaluated from the progression of the $T_{S}=500 \mathrm{~K}$ isotherm in the solid fuel, versus the $10 \mathrm{~m}$ open wind velocity $\left(U_{10}\right)$, is shown in Fig. 1. The results of calculations were also compared with previous numerical results $[21,22]$ obtained in similar conditions and with predictions from two operational empirical model, namely BEHAVE (USA) [23] and MK5 (Australia) [24]. 


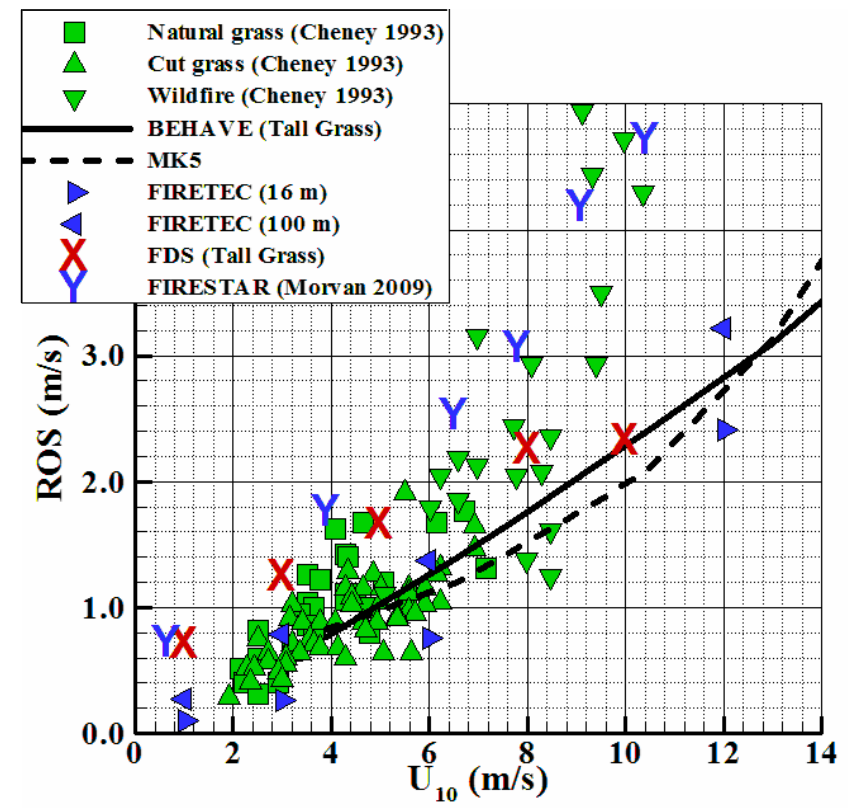

Fig. 1. Rate of spread (ROS) versus $10 \mathrm{~m}$ open wind speed $\left(\mathrm{U}_{10}\right)$ for a standalone surface fire propagating through a grassland.

This curve (Fig. 1) shows that in moderate wind conditions $(<8 \mathrm{~m} / \mathrm{s})$, the ROS of surface fires simulated using FDS was in good agreement with experimental observations. It is important to note that the numerical simulations were carried out using a constant average wind speed. In the simulation, the action of gusts, which can be present in real conditions (on the field), were not taken into account. For stronger wind conditions $\left(U_{10}>8 \mathrm{~m} / \mathrm{s}\right)$, WFDS seemed to underestimate the ROS, this result can be partially explained by the fact that for higher wind conditions, the dimension of the plot along the streamwise direction must be much longer to reach a quasi-steady state propagation for the fire. In the same manner, for stronger wind conditions, the behavior of fire was more affected by border effects, contributing to increase the fire curvature, which were more active because of the small extension of the line fire $(20 \mathrm{~m})$. For data collected during wildfire observations, we cannot fully exclude that other physical mechanisms (not taken into account in the present model), such as spotting for example or turbulence/radiation interaction) could contribute to the propagation of fires. We can notice also, that above the same wind speed threshold $(8 \mathrm{~m} / \mathrm{s})$, the two empirical models (BEHAVE and MK5) under-predicted systematically the ROS values. This result is not so surprising, considering the range of wind conditions (moderate for safety reasons) used to obtain the statistical relations.

Next, we performed a set of numerical simulations, using four values of the $10 \mathrm{~m}$ open wind speed $(1,3,5$ and $8 \mathrm{~m} / \mathrm{s}$ ), by simultaneously igniting two line fires at the upwind and downwind ends of the plot. Two snapshots of calculations representing the solid fuel temperature (in color and in ${ }^{\circ} \mathrm{C}$ ), the heat release rate (HRR $>135 \mathrm{~kW} / \mathrm{m}^{3}$, in orange), and the soot volume fraction (in black), are shown in Fig. 2. These results were obtained for $U_{10}=1 \mathrm{~m} / \mathrm{s}, 10 \mathrm{~s}$ separated these two views. The first one (on top), obtained at time $t=153 \mathrm{~s}$ (33 s after the ignition), represented the situation observed when the two fire fronts were separated by a distance enough $(>20 \mathrm{~m})$ and there is limited interaction between the two fire fronts. We can notice that the temperature of the solid fuel layer located between the two fire fronts, everywhere exceeds $100{ }^{\circ} \mathrm{C}$, indicating that the fuel was there was fully dry. For these conditions, we measured a ROS equal to $0.71 \mathrm{~m} / \mathrm{s}$ for the head fire (for a head fire only case, we also obtained $0.71 \mathrm{~m} / \mathrm{s}$ ) and equal to $0.28 \mathrm{~m} / \mathrm{s}$ for the backfire. This difference was not so large which can be explained by the fact that the behavior of these fires was quite similar and, as shown on Fig. 2, the trajectory of the flame was, weakly deviated by the wind flow. For the two fires, the flames remained quasi-vertical, in this case the propagation of the fire was mainly governed by radiation heat transfer.

The next view (Fig. 2 on bottom), shows the situation observed at time $t=163 \mathrm{~s}$ (43 s after the ignition), during the merging of the two fire fronts. We noticed a significant increase of the flame height (this phenomenon was mainly observed for the backfire). 

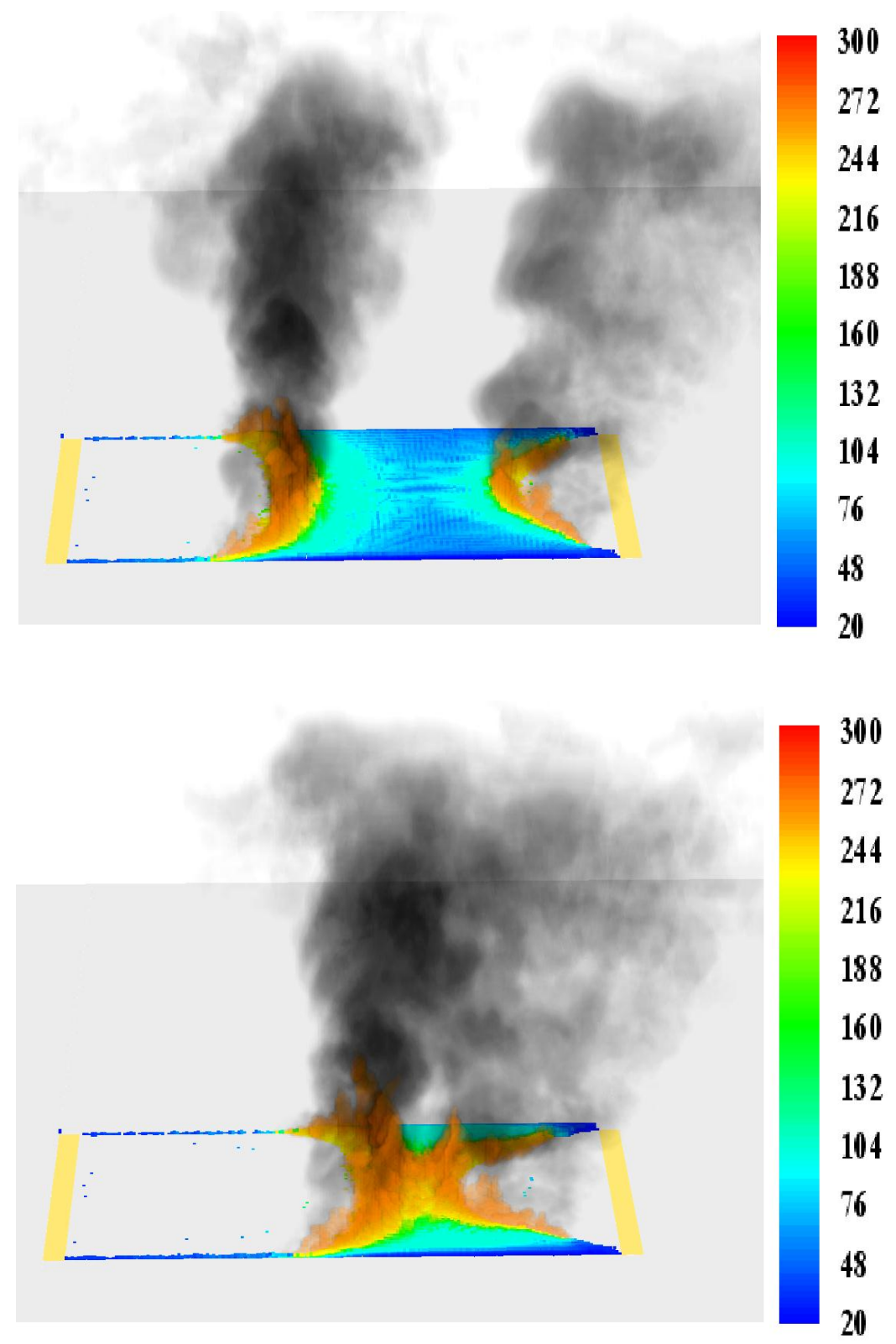

Fig. 2. Heat release rate (value $>135 \mathrm{~kW} / \mathrm{m}^{3}$ ) and surface fuel temperature at time $t=153 \mathrm{~s}$ and $163 \mathrm{~s}(33 \mathrm{~s}$ and $43 \mathrm{~s}$ after the ignition of the two line fires), (10 m open wind speed: $\left.U_{10}=1 \mathrm{~m} / \mathrm{s}\right)$.

A slide along a center plan of the temperature field (gas phase, in ${ }^{\circ} \mathrm{C}$ ) and the streamlines were shown at the same times $(t=153 \mathrm{~s}$ and $t=163 \mathrm{~s})$ in Fig. 3. This representation allowed us to highlight clearly how and at what distance the two fire fronts interacted. When the distance separating the two fire fronts was about $20 \mathrm{~m}$, even if we can notice that the air flow arriving on the backfire had not recover the same behavior than the incoming wind flow (visible on the left hand side), we did not observe a strong interaction between the two fire fronts (Fig. 3 on top). The situation changed suddenly when the distance separating the two fire fronts was around $10 \mathrm{~m}$ (Fig. 3 on bottom), the results showed a sudden increase of the flame height for the backfire and a strong interaction between the two convective plumes. 

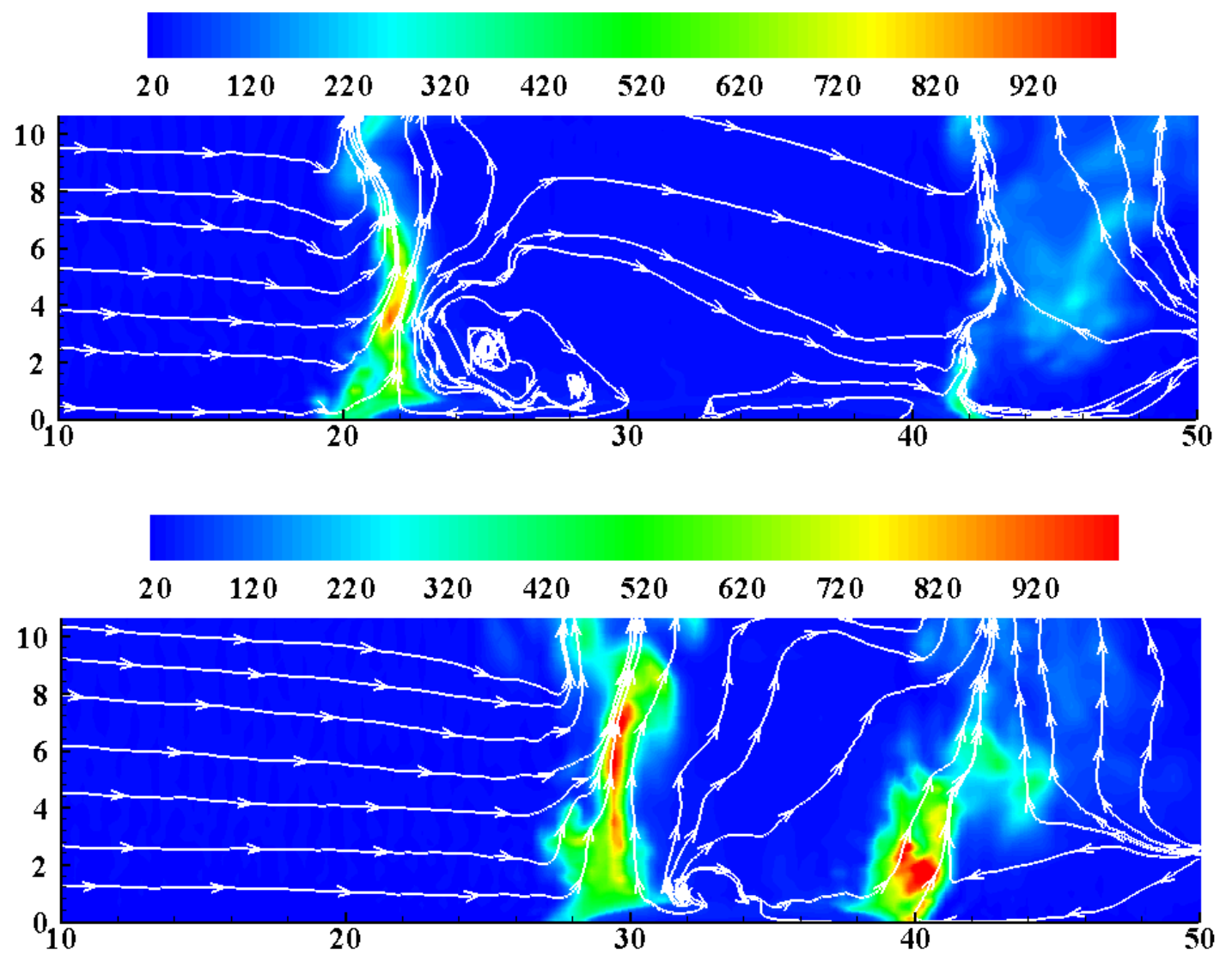

Fig. 3. Slide along a median plan of the temperature field and streamlines at time $t=153 \mathrm{~s}$ and $163 \mathrm{~s}(33 \mathrm{~s}$ and $43 \mathrm{~s}$ after the ignition of the two line fires in grassland; $10 \mathrm{~m}$ open wind speed: $U_{10}=1 \mathrm{~m} / \mathrm{s}$ ).

The role of protection played by the head fire, can be observed in Fig. 4, representing a rake of streamlines emitted $5 \mathrm{~m}$ above the ground level.

We noticed in Fig. 4 that a small part of the incoming wind flow was able to cross the fire front, the main part was deviated vertically and merged with the convective plume. We cannot fully exclude that during the period preceding the merging between the two fire fronts, a small region located between them could be under-oxygenated. This configuration could potentially promote the accumulation of unburned pyrolysis gas, and explain the sudden change of intensity of HRR observed during the merging between the two fires. This sudden change of situation can also be observed in Fig. 5, representing the time evolution of the heat release rate (HRR). To evaluate the modifications resulting from the interaction between the two fire fronts, two curves representing the HRR calculated for a single fire (dashed line) and for two fires (continuous line) were represented on the same graph (Fig.5). The second curve (continuous line) shows clearly that around $t=150 \mathrm{~s}$, the HRR increased progressively, after $t=160 \mathrm{~s}$ this augmentation was more pronounced, reaching a maximum value around $t=168 \mathrm{~s}$, when the two fires merged (see Fig. 5). The time evolution of the pyrolysis front (isotherm $T_{S}=500 \mathrm{~K}$ ) for the head fire and the backfire are represented in Fig. 6 for four values of $U_{10}$ (10 m open wind speed), ranging between 1 and $8 \mathrm{~m} / \mathrm{s}$. For backfires (Fig. 6 on top) all the trajectories are more or less merged, indicating that the ROS (evaluated from the derivative of these curve) was not too much affected by a modification of wind conditions. This result can be easily understood if we consider that backfires are mainly piloted by radiation heat transfer. During the propagation of the backfire, the head fire (on the left hand side in Fig. 2 and Fig. 3) protected as a shelter, the backfire, from the direct action of the wind flow. Consequently even if the wind conditions were modified, the development and the trajectory of the flame above the backfire, were not greatly affected, with the same consequence concerning the heat transfer (mainly by radiation) between the fire and the unburned vegetation. 


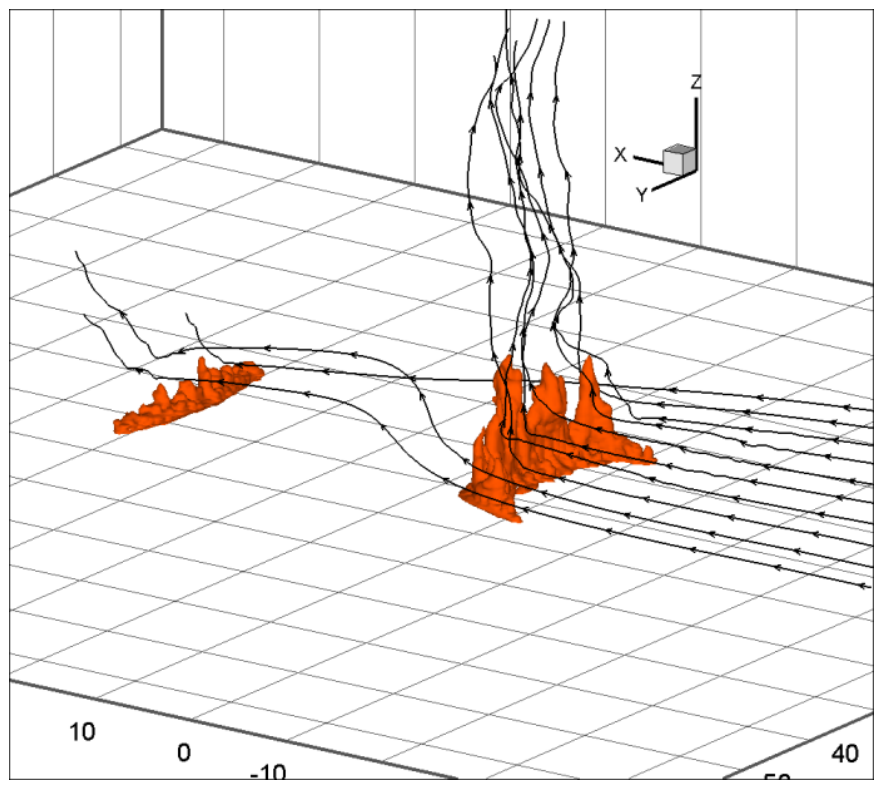

Fig. 4. Streamlines rake emitted at $z=5 \mathrm{~m}$ above the ground level during the propagation of two line fires in grassland (10 m open wind speed: $U_{10}=1 \mathrm{~m} / \mathrm{s}$ ).

The situation concerning the head fire was completely different, by increasing the wind flow, the fire behavior was modified in two ways:

- The flames trajectory was strongly deviated horizontally, to be able to touch more easily the unburned vegetation located ahead of the fire front

- The hot gases released from the combustion reaction were pushed toward the unburned vegetation, which increased the contribution of the convection heat transfer in the energy balance exchanged with the vegetation

The consequence is that as the head fire ROS increased from $0.71 \mathrm{~m} / \mathrm{s}$ to $1.84 \mathrm{~m} / \mathrm{s}$ as the $10 \mathrm{~m}$ open wind speed increased from $1 \mathrm{~m} / \mathrm{s}$ to $5 \mathrm{~m} / \mathrm{s}$. Between $5 \mathrm{~m} / \mathrm{s}$ and $8 \mathrm{~m} / \mathrm{s}$, we observed a saturation effect (probably due to the limited dimensions of the plot) and the ROS decreased from $1.84 \mathrm{~m} / \mathrm{s}$ to $1.74 \mathrm{~m} / \mathrm{s}$.

\section{CONCLUSION}

The interaction between two line fires ignited at the two sides of a grassland plot was simulated using a detailed physical fire model. The vegetation layer was introduced using the "Fuel element model" recently implemented in the 3-D CFD code FDS (Fire Dynamics Simulator V5.5). A set of preliminary simulations was carried out for a single surface fire, the numerical results, especially the evolution of the ROS versus the $10 \mathrm{~m}$ open wind speed, were compared with well documented experimental data collected on experimental fires performed in Australia. The configuration of the simulations was then extended, in igniting a secondary line fire, propagating as a backfire. The numerical results highlighted that, contrary to the expected result, the distance at which the head fire was able to affect significantly the gas flow, did not exceed a distance larger than 10 or $20 \mathrm{~m}$. During the main period between the ignition and the merging between the two line fires, the head fire acted on the backfire as a shelter, by protecting the backfire, from the direct impact of the wind flow. The numerical simulations highlighted also that in many situations, the incoming wind flow was not able to cross the flame front, formed by the head fire. This situation can potentially promote the accumulation of unburned pyrolysis gas between the two fire fronts and explain the sudden increase of HRR observed during the merging phase. This last point must be studied with more attention in a next study. We also plan in future, to simulate the interaction between two fire fronts, in more realistic configurations, including also slope effects. These configurations will be more representative of those retained during extinction fire operation. 


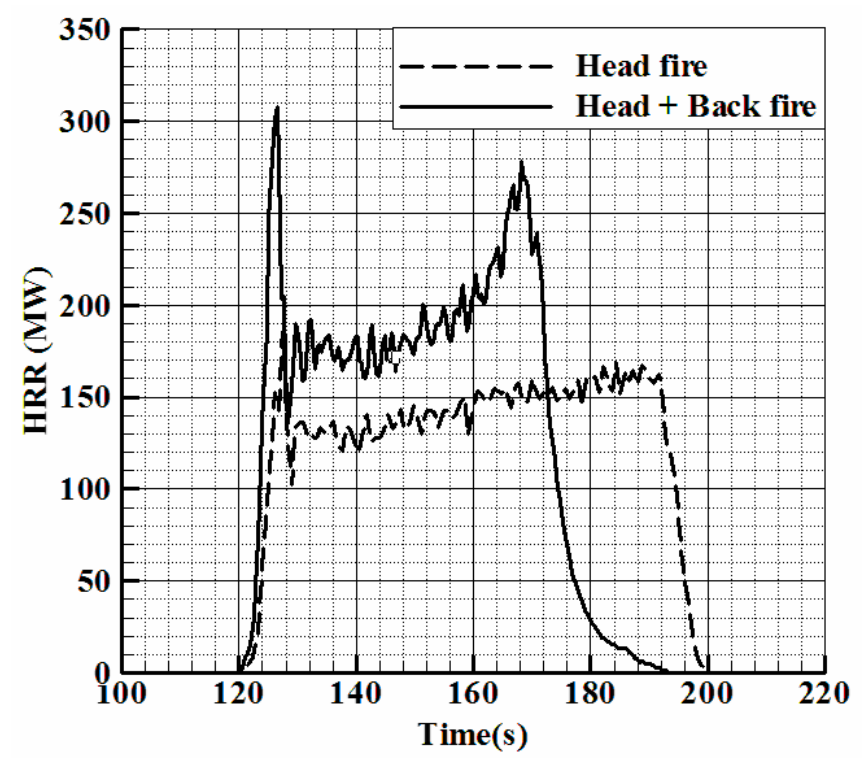

Fig. 5. Heat release rate calculated during after the ignition of one (dashed line) and two (continuous line) in grassland (10 m open wind speed: $U_{10}=1 \mathrm{~m} / \mathrm{s}$ ).

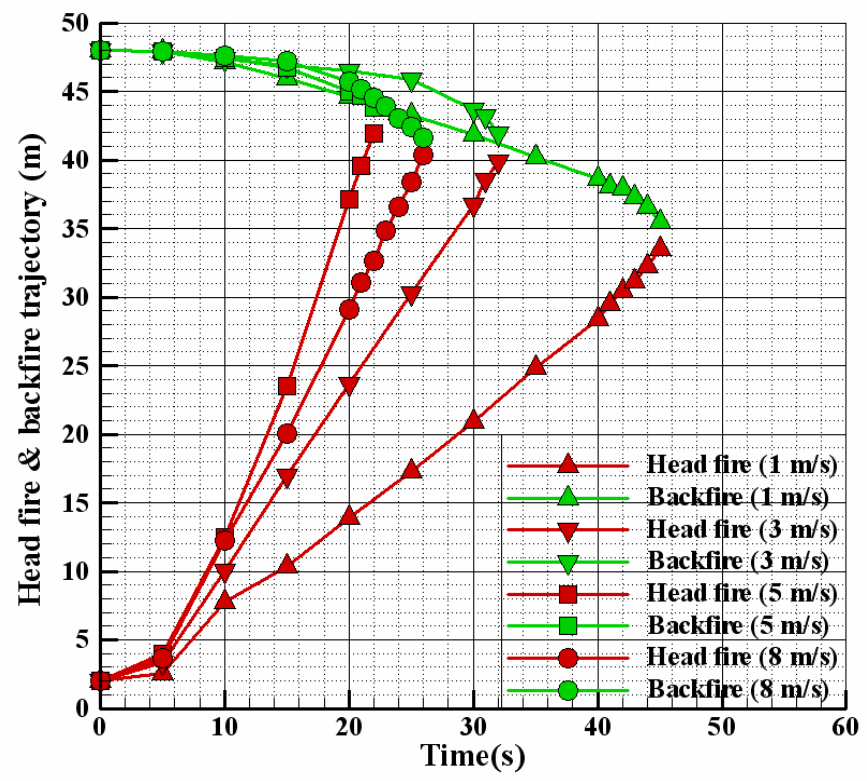

Fig. 6. Time evolution of the position of fire fronts (isotherm $T=500 \mathrm{~K}$ ), backfire on top and head fire on bottom.

\section{REFERENCES}

[1] Pyne S.J., Andrews P.L., and Laven R.D. Introduction to Wildland Fire ( $2^{\text {nd }} e d$ ), John Wiley \& Sons, 1996, p. 55.

[2] Stocks B.J., and Hartley G.R., "Fire behavior in three jack pine fuel complexes", Tech. Report, Great Lakes Forestry Centre, Sault Sainte Marie, Ontario, 1995, 16 p.

[3] Rehm R.G., Hamins A., Baum H.R., McGrattan K.B., and Evans D.D. "Community-scale fire spread", National Institute of Standards and Technology Report NISTIR 6891, Gaithersburg, MD, $2002,17 \mathrm{p}$. 
[4] Forgarty L.G., and Alexander M.E., (1999) A field guide for predicting grassland fire potential: derivation and use, Fire Technology Transfer Note, 20, 10 p.

[5] Chandler C., Cheney P., Thomas P. and Trabaud L., Fire in forestry, 1983, Vol.1 \& 2, John Wiley $\&$ Sons.

[6] Goldammer J.G. and DeRonde C., Wildfire fire management handbook for sub-Sahara Africa, Global Fire Monitoring Center (GFMC), 2004, 446 p.

[7] Cui W., and Qiao Q., (2002), Experimental studies of interactions between backfires and coming surface fires, Forestry studies in China 4(1): 25-28.

[8] Vega J.A., Jiménez E., and Pérez J.R., "Effectiveness of suppression fires : methods and first results", Deliverable D2.3-2 of the Integrated project FireParadox, project n ${ }^{\circ} \mathrm{FP6}-018505$, European Commission, 2008, 27 p.

[9] Vega J.A., Jiménez E., Fernandez C., Dupuy J.L., and Linn R.R., "Effectiveness of suppressions fires in shrublands: final achievements", Deliverable D2.2-5 of the Integrated project FireParadox, project n ${ }^{\circ}$ FP6-018505, European Commission, 2010, 25 p.

[10] Roxburgh R., and Rein G., "Study of wildfire in-draft flows for counter fire operations", Proceedings of Forest Fire 2008, International Conference on Modelling, Monitoring and Management of Forest Fires, Toledo, 2008, Spain, 10 p.

[11] Morvan D., Hofman C., Rego F., and Mell W., "Numerical simulation of the interaction between two fire fronts in the context of suppression fire operation", Proceedings of the $8^{\text {th }}$ Symposium on Fire and Forest Meteorology, 13-15 October 2009, Kalispell, MT-USA.

[12] Dupuy J.L., Konovalov V., Pimont F., Vega J.A., Jiménez E., and Linn R.R., "Simulations of interacting fire fronts", Deliverable D2.3-2 of the Integrated project FireParadox, project n ${ }^{\circ}$ FP6018505, European Commission, 2010, 25p.

[13] Cheney N.P., Gould J.S., and Catchpole W.R. (1993) The influence of fuel, weather and fire shape variables on fire spread in grasslands, Int. J. Wildland Fire, 3(1): 31-44. http://dx.doi.org/10.1071/WF9930031

[14] Cheney P., and Sullivan A., Grassfires: Fuel, weather and fire behaviour (2 ${ }^{\text {nd }}$ ed), CSIRO Publishing, 2008, $150 \mathrm{p}$.

[15] Morvan D., and Dupuy J.L., (2004), Modelling the propagation of a wildfire through a Mediterranean shrub using a multiphase formulation, Combustion and Flame, 138: 199-210. http://dx.doi.org/10.1016/j.combustflame.2004.05.001

[16] Mell W., Maranghides A., McDermott R., and Manzello S.L., (2009), Numerical simulation and experiments of burning Douglas fir trees, Combustion and Flame, 156: 2023-2041. http://dx.doi.org/10.1016/j.combustflame.2009.06.015

[17] McGrattan K.B., Hostikka S., Floyd J., Baum H., Rehm R., Mell W., and McDermott R., "Fire Dynamics Simulator Technical Reference Guide, Vol.1 Mathematical model", NIST Special Publication 1018-5, National Institute of Standards and Technology, Gaithersburg, Maryland, September 2010. http://fire.nist.gov/fds/documentation.html (accessed 2010-09-27).

[18] Ritchie, S.J., Steckler, K.D., Hamins, A., Cleary, T.G., Yang, J.C. and Kashiwagi, T., 1997. The Effect of Sample Size on the Heat Release Rate of Charring Materials. Fire Safety Science 5: $177-$ 188. http://dx.doi.org/10.3801/IAFSS.FSS.5-177

[19] Mell W., Jenkins M.A., Gould J., and Cheney P., (2007), A physics based approach to modelling grassland fires, Int. J. Wildland Fire, 16: 1-22. http://dx.doi.org/10.1071/WF06002

[20] Morvan D., (2010), Physical phenomena and length scales governing the behaviour of wildfires: A case for physical modelling, Fire Technology, 47: 437-460. http://dx.doi.org/10.1007/s10694-010$\underline{0160-2}$ 
[21] Linn, R.R., and Cunningham, P., (2005), Numerical simulations of grass fires using a coupled atmosphere-fire model: basic fire behavior and dependence on wind speed, J. of Geophysical Research, 110, Issue D13. http://dx.doi.org/10.1029/2004JD005597

[22] Morvan D., Méradji S., and Accary G., (2009), Physical modelling of fire spread in grasslands, Fire Safety Journal, 44: 50-61. http://dx.doi.org/10.1016/j.firesaf.2008.03.004

[23] Andrews P.L., "BehavePlus fire modelling system: past, present and future", Proceedings of 7th Symposium on Fire and Forest Meteorological Society. 23-25 October 2007, Bar Harbor, Maine, $13 \mathrm{p}$.

[24] McArthur A.G., "Grassland fire danger meter MkV", CSIRO Division of Forest Annual Report 1976-1977, 58 p. 